\title{
Relation between Performances of the Air-Depolarized Cell and Catalytic Activity of Charcoals
}

\author{
Yoshiyuki MAKI*
}

By $\operatorname{Berl}^{(1)}$ and Weisz ${ }^{(2)}$ the production of peroxyl ion and its catalytic decomposition was acknowledged at the cathode process of the air-depolarized cell and the cathode potential was determined by the thermodynamic relation between peroxyl ion and partial pressure of oxygen at the electrode surface. According to the theory it is the most important thing to select a charcoal as a cathode material which react as a strong catalyst for aqueous solution of hydrogen peroxyde. But it has been often experienced that a charcoal which has strong decomposition ability for aqueous solution of hydrogen peroxyde shows poor discharge characteristics when the air-depolarized cell is constructed from the charcoal. On the contrary a charcoal which has poor catalytic activity shows better characteristic than the former ${ }^{(3)}$. It is assumed that the result opposite to the theory is caused by the comparison among charcoals which differ from each other in physical state-density, surface area and particle size distribution, and by the method of discharge characteristic measurement. To make sure this assumption surface complexes of charcoal are prepared without changing any physical state of coal by treating with ammonia, chlorine and oxygen at a temperature ranging from 400 to $800^{\circ} \mathrm{C}$. The resulting charcoals contain nitrogen, chlorine and oxygen by chemisorption (Fig. 1) and differ only in catalytic activity. Ammonia and chlorine adsorbed physically by the reaction are eliminated sufficiently by washing with hot water.

Acid and base adsorption of each surface complex are shown in Fig. 2 and 3 . The order of base

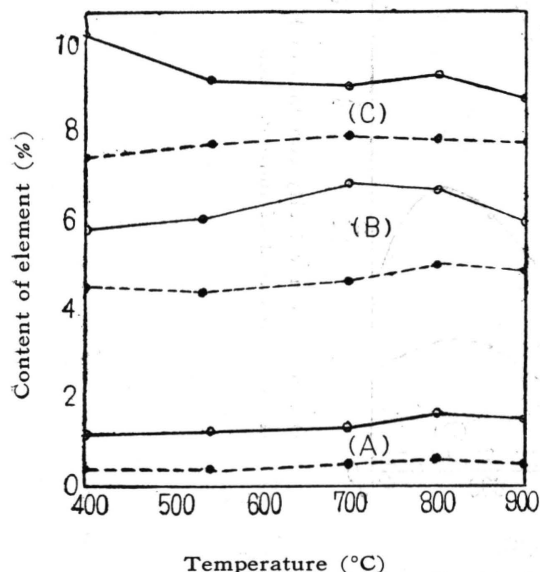

$\begin{array}{ll}\text { (A) Nitrogen compex } & \text { (B) Oxygen complex }\end{array}$

(C) Chlorine complex

...... Hard coal of the oak

- : Soft coal of the pine

Fig. 1 Content of nitrogen, oxygen and chlorine in the surface complexes of charcoal.

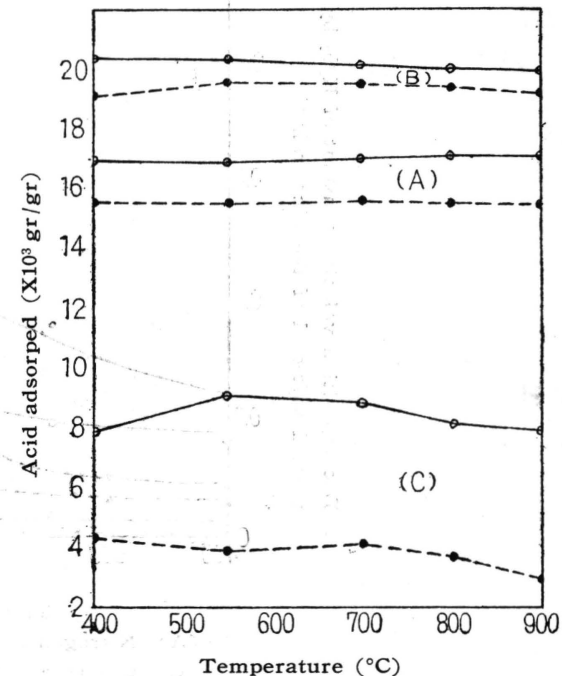

$\begin{array}{ll}\text { (A) Nitrogen complex } & \text { (B) Oxygen complex }\end{array}$

(C) Chlorine complex

...... : Hard coal of the oak

- Soft coal of the pine

Fig. 2 Adsorption of acid by the surface complexes of charcoals

* The Electrotechnical Laboratory (Agency of Industrial Science and Technology)

1, Nagata-cho, Chiyodaku. Tokyo

The original written in Japanese can be seen in J. Electrochem. Soc. Japan, 27256 (1959) 
adsorption value is chlorine complex, nitrogen complex and oxygen complex and that of acid adsorption is in the reverse order of base adsorption Acid adsorption of each complex hardly changes by the treating temperature. Base adsorption of nitrogen complex and chlorine complex gradually increases from the temperature of about $700^{\circ} \mathrm{C}$ and of oxygen complex decrease from the same temperature. Surface complexes prepared from soft coal of the pine show higher adsorption value of acid and base than from hard charcoal of the oak.

The order of catalytic activity for the decomposition of aqueous hydrogen peroxyde is nitrogen, oxygen and chlorine complex. (Fig. 4) The catalytic activity of chlorine complex markedly decrease than the coal before treating. The surface complexes from soft coal show higher activity for hydrogen peroxyde than that of hard coal by ten to twenty times. The decomposition velocity shows maximum at the treating temperature of about $850^{\circ} \mathrm{C}$ but this is not dis-

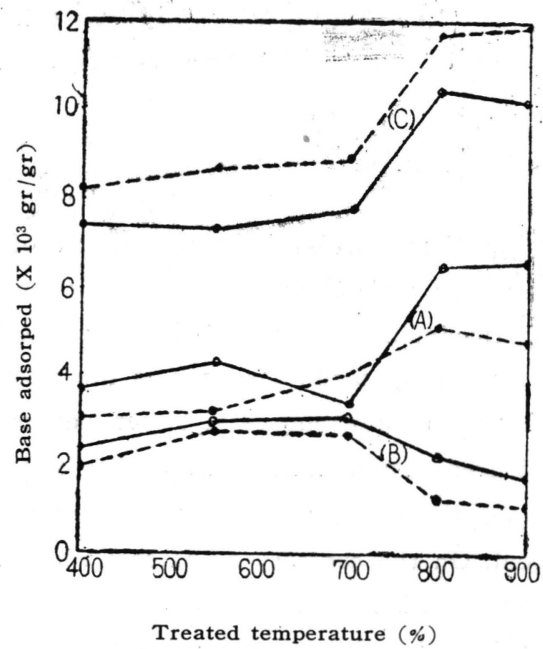

$\begin{array}{ll}\text { (A) Nitrogen complex } & \text { (B) Oxygen complex }\end{array}$

(C) Chlorine complex

….. : Hard coal of the oak

- : Soft coal of the pine

Fig. 3 Adsorption of base by the surface complexes of charcoals.

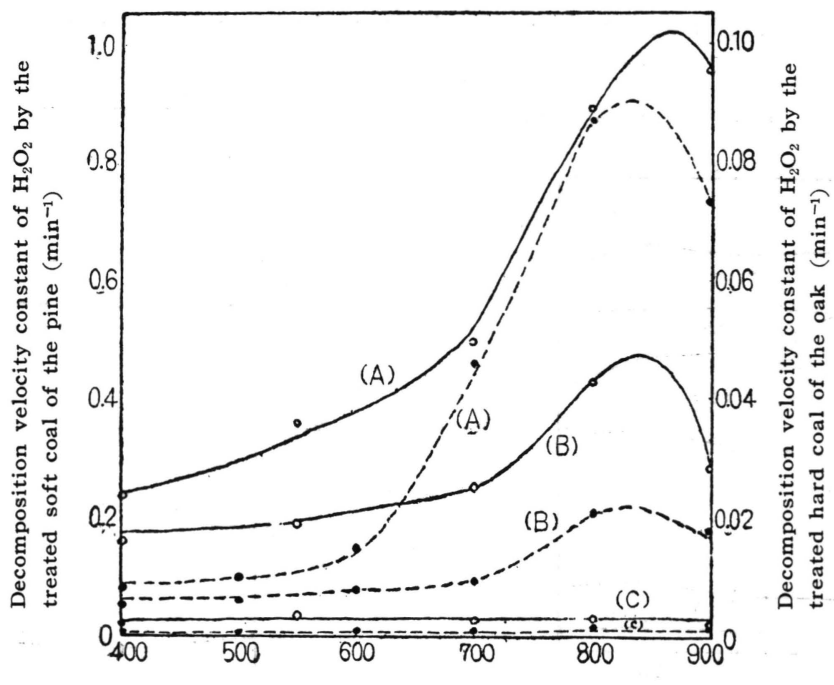

Treated temperature $\left({ }^{\circ} \mathrm{C}\right)$

$\begin{array}{ll}\text { (A) Nitrogen complex } & \text { (B) Oxygen complex }\end{array}$

(C) Chlorine complex

...... Hard coal of the oak _ Sof coal of the pine

Fig. 4 Treated temperature and decomposition velocity of hydrogen peroxyde.

teristics of the air-depolarized cell constructed using these complexes are shown in Fig. 5 . In order to measure the discharge characteristics of the cell as reproducible as possible and to prevent physical and chemical change of the coal, without adding any binder and without sintering, the sample treated with $5 \%$ paraffine wax solution of benzene is pressed under the pressure of $100 \mathrm{~kg} / \mathrm{cm}^{2}$ for thirty min- 


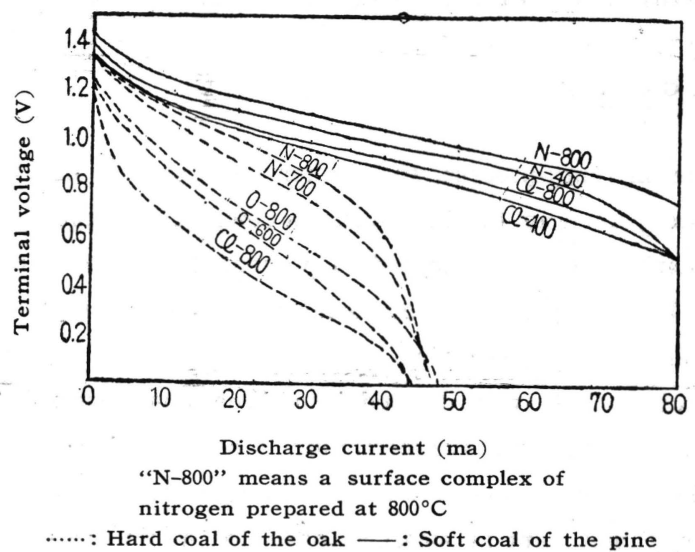

Fig. 5 Discharge characteristics of the surface complexes of charcoals.

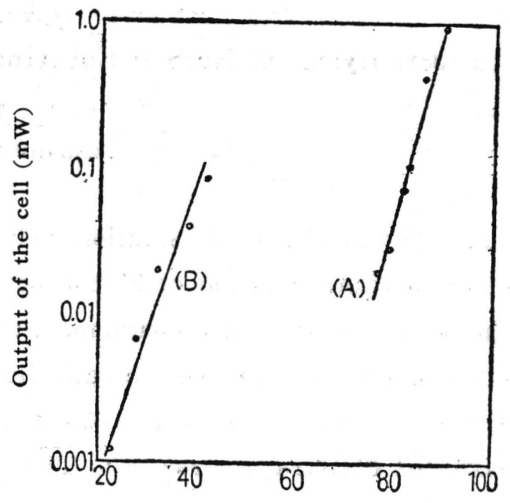

Decompositon velocity constant $\left(\mathrm{min}^{-1}\right)$

(A), Soft coal of the pine

(B), Hard coal of the oak

Fig. 6 Relation between the output of the cell and decomposition velocity of hydrogen peroxyde.

utes in a metal tube which is plated with nickel and serves as well for terminal of the cathode.

Only the bottom surface of the tube contributes as a reaction surface. By this method we can measure the characteristics of cells within $2 \%$ of deviation. Nitrogen complexes of charcoal generally show better perfomance than oxygen and chlorene complexes. Discharge characteristics of surface complexes from hard coal are remarkably inferior to that of sof coal.

Between the performance of cell and the catalytic activity of charcoal as ahown in Fig. 6 a definite relation, $\log K=a+b w(K$; velocity constant, $w$; output of the cell, $a, b$; numerical constant) is recognized at the coal derived from the same source, but there is no relation between charcoals whose physical state differs from each other. From above mentioned result it is confirmed that the higher catalytic activity of charcoal is not a sufficient condition but a necessary condition as a cathode material of the air-depolarized cell.

(Received January 26, 1959)

\section{Literature :}

(1) W.G. Berl : Trans. Electrochem. Soc. 83258 (1943)

(2) R.S. Weisz, S. Jaffe : ibid 83128 (1948)

(3) K. Bratzer : Z. Electrochem. 5481 (1950) 